\title{
LA IMAGEN DE ROSA LUXEMBURG' EN LA PRENSA MADRILEÑA (1899-1922)
}

\section{THE IMAGE OF ROSA LUXEMBURG IN THE MADRID PRESS (1899-1922)}

\author{
María Sánchez Mellado \\ Universidad Pablo de Olavide, Sevilla, España \\ maria.sanchez.mellado2@gmail.com
}

Recibido: noviembre de 2019

Aceptado: diciembre de 2019

Palabras clave: Rosa Luxemburg, periódicos, agenda-setting, opinión pública.

Keywords: Rosa Luxemburg, newspapers, agenda-setting, public opinion.

Resumen: Uno de los pocos canales a través de los cuales la población madrileña pudo informarse y conocer a Rosa Luxemburg de manera (casi) instantánea fueron los periódicos. Estos, como ha demostrado la teoría de la agenda-setting, acaban influyendo en la opinión pública al resaltar y describir de determinadas formas los temas y las personas. Debido a ello, resulta de interés conocer qué imagen dieron los periódicos de Luxemburg, qué aspectos de ella destacaron y cómo la describieron para tener una aproximación a cómo la ciudadanía la percibió y qué conoció sobre ella.

Abstract: One of the few channels through which the population of Madrid could get information and meet Rosa Luxemburg in an (almost) instantaneous way were the newspapers. These, as the theory of agenda-setting has shown, influence public opinion by highlighting and describing subjects and people in certain ways. Because of this, it is interesting to know what the image of Luxemburg was in the newspapers, what aspects of her were highlighted and how they described her in order to have an idea of how citizens perceived her and what they knew about her.

\section{l. Introducción}

El estudio analiza la imagen que dio la prensa madrileña de Rosa Luxemburg ya que los periódicos fueron claves en la transmisión de unos hechos y unas opiniones que no estaban al alcance directo de los españoles. Luxemburg no era una sindicalista

1. Se adopta la versión original del nombre, aunque en los periódicos analizados, como ser verá en algunas de las citas utilizadas, aparece la versión castellanizada con Rosa Luxemburgo. Lo mismo ocurre con los socialistas alemanes Karl Liebknecht (Carlos Liebknecht) o August Bebel (Augusto Bebel), entre otros. 
española o un político al que la población pudiera escuchar en un mitin, sino que vivía en Alemania por lo que la lejanía dificultó que la población española pudiera saber de ella. Uno de los pocos medios que tuvieron para saber quién fue y qué ideología defendió fueron los periódicos. Por ello, la investigación ahonda en la imagen que de ella dieron los impresos con la intención de hacer una aproximación a cómo la población la percibió. Partiendo de esta idea, se analiza qué imagen de Luxemburg llegó a los españoles, qué ideas políticas y económicas de ella se transmitieron y cómo esa imagen fue cambiando conforme aumentó su presencia en los medios. El objetivo es acercarse a la imagen que tuvo la población madrileña de Luxemburg para, desde el punto de vista de la agenda-setting, comprender cómo los periódicos conforman la visión política de la ciudadanía.

La investigación se estructura en una primera parte metodológica en la que se explica la teoría que se ha empleado, los periódicos analizados y las etapas en las que se ha dividido la aparición de Luxemburg en la prensa. A continuación se desarrollan cada una de las etapas con los principales aspectos que destacaron los periódicos para llegar a la conclusión de que Rosa Luxemburg fue un personaje de interés para los periódicos y para la sociedad y a la que vincularon, sobre todo los periódicos liberales y de izquierdas, de forma positiva con el antirevisionismo y el pacifismo.

\section{Metodología}

La investigación se apoya en la teoría de la agenda-setting la cual sostiene: 1) que los temas más importantes para la prensa son también los más importantes para la población, y 2) que los atributos de descripción que emplean los medios de comunicación son los utilizados por sus usuarios. ${ }^{2}$ Esto quiere decir que, en función de lo que ha leído en los medios de comunicación, la población destaca y describe unos temas, sobre todo en relación con aquellos acontecimientos o personas a los que no puede acceder por la experiencia directa. ${ }^{3}$ Así, a partir de las informaciones obtenidas de la prensa, la población define y construye su realidad que, dado los componentes ideológicos de los periódicos, no tiene que ver con la realidad. Son como las sombras sobre la pared de la caverna. ${ }^{4}$ Debido a ello, en la investigación que ahora se presenta, las noticias no se han estudiado como la verdad, sino como una verdad que llegó a España y con la que los españoles construyeron su mundo.

Los estudios sobre la teoría de la agendasetting tienen dos ramas: el análisis de la agenda mediática, es decir, del contenido de los medios de comunicación; y el estudio de la agenda pública realizada a través de encuestas de opinión. Aunque en el periodo en el que se basa la investigación no existían encuestas de opinión, sí es posible realizar un estudio de agen-

2. McCombs, M. E. y Shaw, D. L. (1972) "The Agenda-Setting function of mass media", The Public Opinion Quarterly, núm. 36 (2), pp. 176187; McCombs, M. E. y Evatt, D. (1995) "Los temas y los aspectos: Explorando una nueva dimensión de la agenda setting", Comunicación y Sociedad, núm. 8 (1), pp. 7-32.

3. Zucker, H. G. (1978) "The Variable Nature of News Media Influence”, en Ruben, B. D. (ed.) Communication Yearbook 2, New Jersey, Transaction, pp. 225-240.

4. Shaw, D. L. y Martin, S. E. (1992) "The Function of Mass Media Agenda Setting”, Journalism \& Mass Communication Quarterly, núm. 69 (4), pp. $902-920$, p. 917. 
da-setting al existir una base empírica de investigaciones que han demostrado sus efectos, por lo que el estudio es extrapolable a cualquier época en la que exista una prensa abierta y personas interesadas y alfabetas, ${ }^{5}$ es decir, con capacidad de leer los periódicos bien directamente o bien con ayuda de un intermediario.

Para conocer la imagen que dio la prensa madrileña de Luxemburg se ha realizado un análisis de contenido de las noticias que la mencionaron. La investigación se centra en los periódicos de Madrid porque disponían de una mayor tecnología, mayor disponibilidad de fuentes de información, mayor número de páginas y mayor difusión que los periódicos de provincias. ${ }^{6}$ Así, se han incorporado los siguientes periódicos que, clasificados por ideologías, son: los liberales El Fígaro, El Globo, El Imparcial, El Liberal, El Sol, España, Heraldo de Madrid, La Lectura, La Libertad, La Mañana y La Voz; los conservadores ABC, Blanco y Negro, El Día, La Acción, La Época y La Nación; los católicos La Lectura Dominical, Revista Católica de Cuestiones Sociales, y Revista Iberoamericana de Ciencias Eclesiásticas; el carlista El Correo Español; el integrista El Siglo Futuro; los militares El Heraldo Militar y La Correspondencia Militar; los republicanos El País y El Radical; el anticlerical republicano El Motín; los socialistas Acción Socialista, El Socialista y Vida Socialista;

5. Caudill, E. (1997) “An Agenda-Setting Perspective on Historical Public Opinion", en McCombs, M. E., Shaw, D. L. y Weaver, D. (eds.) Communication and democracy. Exploring the intellectual frontiers in agenda-setting theory, New Jersey, Lawrence Erlbaum Associates, Publishers, pp. 169-182.

6. Para conocer bien la prensa de aquella época: Cruz Seoane, M. y Sáiz, M. D. (1998) Historia del periodismo en España. 3. El siglo XX: 18981936, Madrid, Alianza Editorial. el independiente La Correspondencia de España; así como las revistas Cosmópolis, El Financiero, España y América, La Esfera, La Ilustración Española y Americana, Nuestro Tiempo y Nuevo Mundo; y el anuario El Año Político. ${ }^{7}$

Tras el análisis de los periódicos, y atendiendo también a los sucesos internacionales, se han clasificado las noticias en cuatro etapas (tabla 1): Luxemburg "la rechazada", Luxemburg "la rebelde pacifista", Luxemburg "la mártir" y en recuerdo de Luxemburg.

Bajo la denominación de Luxemburg, "la rechazada" se han agrupado las noticias del periodo 1899-1913 en las que se identificó a Luxemburg como un miembro más del socialismo alemán, sobre todo al hacer referencia a los Congresos, ya sean del Partido Socialista Alemán (SPD) o de la Internacional Socialista, en los que participó activamente con la defensa de la huelga general, el sufragio universal, además de mostrarse contraria hacia el revisionismo y la guerra. Sobre ellos, la posición de Luxemburg fue opuesta a la de la mayoría y también a la de los líderes de su partido y sus ideas fueron rechazadas. Sin embargo, no destacó como protagonista de las informaciones sino por ser una más de las personas que componían el SPD. Hecho que se revertirá en la siguiente eta-

7. Los archivos digitalizados se encuentran disponibles en la hemeroteca digital de la Biblioteca Nacional de España (http://www.bne. es/es/Catalogos/HemerotecaDigital/), la hemeroteca de $A B C$ (http://hemeroteca.abc.es/) y el archivo digitalizado de la Fundación Pablo Iglesias (http://archivo.fpabloiglesias.es/index. php? $\mathrm{r}=$ hemeroteca/ElSocialista) [Fecha de consulta de las tres direcciones webs: 07-12-2019]. Para conocer más sobre las ideologías de los periódicos: Cruz Seoane, M. y Sáiz, M. D. (1998) Historia del periodismo.... 


\section{Tabla l. Número de noticias anuales en las que aparece Rosa Luxemburg y su relación con los acontecimientos que tuvieron lugar.}

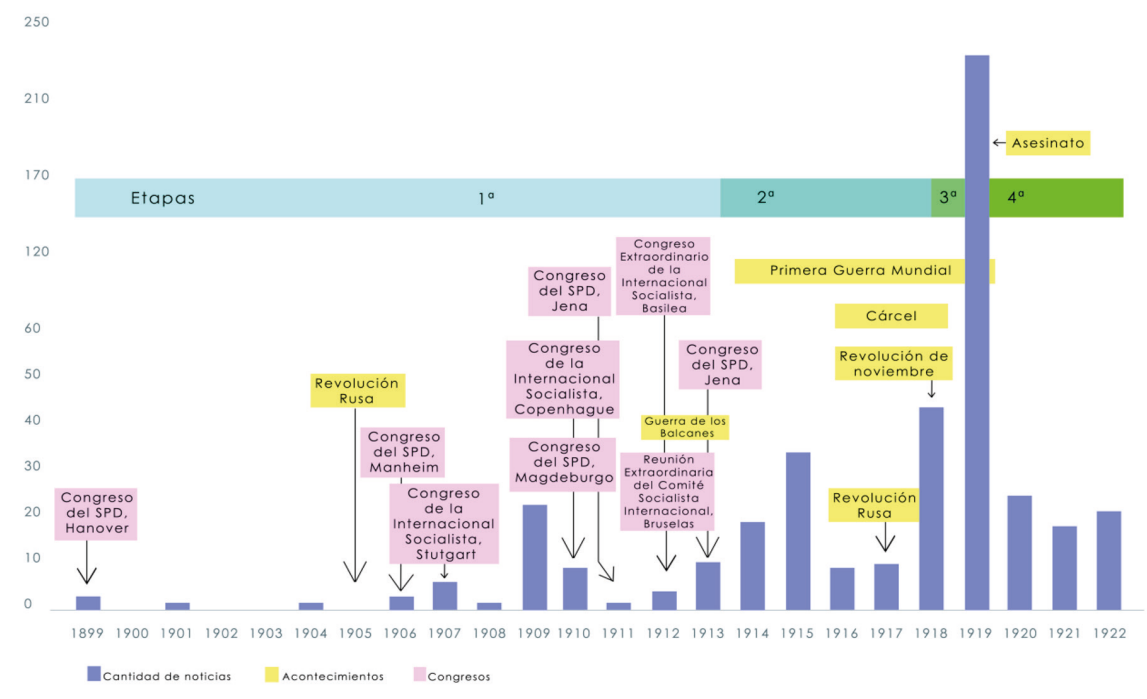

Fuente: Elaboración propia tras el análisis de los periódicos.

pa, Luxemburg "la rebelde pacifista", que comprende desde 1914 hasta mediados de 1918 y supone un aumento en el número de noticias en las que se informó de Luxemburg, sobre todo por su oposición a la guerra mundial (su rebeldía pacifista) y por su encarcelamiento.

Una tercera fase abarca los siete meses que van desde julio de 1918 hasta febrero de 1919 con la denominación de Luxemburg "la mártir". Fueron los meses en los que más noticias hubo sobre ella ya que se produjo la revolución alemana de noviembre, su liberación y su asesinato. Además, Luxemburg ya no era una desconocida y a partir de su salida de la cárcel en noviembre de 1918 y de su participación en la revolución la prensa publicó informaciones sobre su vida, la relacionó con la revolución rusa y reaccionó ante su asesinato.

Finamente, desde marzo de 1919 hasta finales de 1922 hay una última etapa en la que, con el nombre de en recuerdo de Luxemburg, se recogen noticias que la evocaban junto con informaciones del juicio a sus asesinos. Fue un periodo de abundantes noticias, pero dispares y dispersas, en las que la importancia de Luxemburg adquirida años atrás contribuyó a que siguiera siendo noticiable.

A continuación se detallan cada una de las etapas en las que se ve en qué aspectos de Luxemburg se centró la prensa y cómo su imagen fue evolucionando.

\section{Luxemburg "la rechazada" (1899-1913)}

La primera información sobre Luxemburg en la prensa fue en 1899 con motivo de su participación en el Congreso de los socialistas alemanes en Hanover, pero no como protagonista, sino como una más 
de las personas que componían el SPD. Así lo evidenciaron el periodista socialista Juan José Morato, ${ }^{8}$ en el Heraldo de Madrid, y el semanario El Socialista quienes, aunque no dijeron nada sobre las propuestas que Luxemburg hizo, sí la identificaron como uno de «los hombres más notables del socialismo alemán» junto con Karl Kaustky, Karl Liebknecht o Clara Zetkin, entre otros. ${ }^{9}$

A partir de entonces, y sobre todo desde 1906, las referencias a Luxemburg en la prensa aumentaron destacando, principalmente, cuatro de sus ideas: 1) el antirevisionismo, 2) la huelga general, 3) el sufragio universal y 4) el pacifismo. A continuación se explican cómo fueron acogidas estas cuatro ideas en la prensa.

\section{3.l. Luxemburg contra el revisionismo}

Con Eduard Bernstein como principal exponente, la idea revisionista sostiene que no es necesaria una revolución obrera, sino que desde el propio sistema capitalista, de forma pacífica, evolutiva y empleando la acción parlamentaria se pueden hacer las reformas necesarias. ${ }^{10}$ EI SPD no reaccionó al revisionismo hasta que Luxemburg se pronunció en su contra a través de una serie de artículos que

8. Castillo, S. (2005) Trabajadores, ciudadania y reforma social en España: Juan José Morato (1864-1938), Madrid, Siglo XXI de España.

9. "El mundo obrero", Heraldo de Madrid, 2210-1899, p. 4; "Congreso socialista alemán”, El Socialista, 27-10-1899, p. 2. El Socialista no fue periódico diario hasta 1913.

10. Bernstein, E. (1982) Las premisas del socialismo y las tareas de la socialdemocracia. Problemas del socialismo. El revisionismo, Madrid, Siglo Veintiuno. posteriormente serían publicados con el título "Reforma o Revolución" y en los que Luxemburg tachó la idea revisionista de oportunista y que ya había sido refutada por el marxismo. ${ }^{11}$

La postura antirevisionista de Luxemburg se desarrolló poco en la prensa pues solamente se han encontrado tres alusiones a ella: una neutra y otras dos positivas. La neutra fue en una revista mensual católica con una breve reseña que el párroco M. Hidalgo escribió en el año 1901 de la obra de Luxemburg La crisis socialista en Francia: el caso Millerand y los partidos socialistas. Hidalgo explicó que, poniendo a Francia como ejemplo, Luxemburg había criticado la participación de los socialistas en los ministerios burgueses, es decir, el revisionismo, lo que para ella era, como indicó Hidalgo, «absurdo» y un «retroceso». ${ }^{12}$

Las dos menciones positivas a Luxemburg por su antirevisionismo aparecieron en publicaciones socialistas. La primera fue de Antonio Fabra Rivas, ${ }^{13}$ que escribía informaciones del socialismo alemán para El Socialista, sobre una conferencia impartida por Luxemburg de quien Fabra Rivas destacó que era «en el terreno de la teoría (...) una de las primeras inteligencias de nuestro Partido». En dicha conferencia Luxemburg criticó la tendencia revisionista que consideraba el parlamentarismo como el único medio para que el socialismo alcanzase su objetivo, ob-

11. Luxemburgo, R. (2015) Reforma o Revolución, Madrid, Ediciones Akal.

12. "Alemanas", Revista ibero-americana de ciencias eclesiásticas, 1901, p. 484.

13. Periodista catalán que firmaba con el pseudónimo Mario Antonio. Martínez de Sas, M. T. (2008) "Antonio Fabra Ribas, un socialista políticamente incorrecto", Boletín de la Real Academia de la Historia, núm. 205 (3), pp. 345-392. 
viando con ello las dificultades que tiene para obtener una mayor representación parlamentaria. Luxemburg veía como necesidad para alcanzar su meta obtener la mayoría del pueblo, pero no identificaba la mayoría del pueblo con la mayoría de los electores. ${ }^{14}$ La segunda referencia positiva sobre la postura contraria al revisionismo de Luxemburg la hizo el político francés Charles Rappoport en las páginas de la revista Vida Socialista cuando criticó "la adaptación del socialismo al espíritu y al medio burgués» y alabó «las brillantes refutaciones de Kautsky, de Piekhanoff, de Rosa Luxemburg [que] han vencido las teorías burguesas del revisionismo». ${ }^{15}$

La prensa empezaba a diferenciar, y lo continuará haciendo en los siguientes años, dos grupos dentro del socialismo alemán: los que estaban a favor del revisionismo y los que no, o entre los «reformistas y los revolucionarios puros» ${ }^{16}$ al que pertenecía Luxemburg.

\subsection{Luxemburg a favor de la huelga de masas}

Para Luxemburg la huelga de masas era «el mismo movimiento de la masa proletaria, la forma en que se manifiesta la lucha proletaria en la revolución ${ }^{17}$ gracias a la cual el socialismo alemán había consegui-

14. "En Alemania. Una conferencia de Rosa Luxemburgo", El Socialista, 05-04-1907, p. 3; "En Alemania. Una conferencia de Rosa Luxemburgo. (Conclusión)", El Socialista, 12-04-1907, p. 3.

15. "El Congreso de la Internacional socialista en Copenhague", Vida socialista, 23-10-1910, p. 5.

16. "Los socialistas alemanes", La mañana, 1709-1911, p. 1.

17. Luxemburgo, R. (2003) Huelga de Masas, Partido y Sindicato, Madrid, Fundación Federico Engels., p. 53. do más mejoras en la legislación obrera que con la acción de sus representantes en el Parlamento. ${ }^{18}$

Los periódicos destacaron cómo Luxemburg puso la revolución rusa de 1905 como ejemplo del éxito del empleo de la huelga general. ${ }^{19}$ Para ella, la huelga de los obreros rusos había sido «un arma (...) efectiva» contra la burguesía capitalista y animó a imitarlos. ${ }^{20}$ De hecho, la prensa destacó cómo la misma Luxemburg participó activamente por el triunfo de la revolución. ${ }^{21}$

Sin embargo, y según las informaciones ofrecidas por los periódicos, la mayoría del SPD no veía que en Alemania fuera el momento para recurrir al empleo de la huelga general. F. Von der Tauber firmó una noticia para El Correo Español en la que explicaba que August Bebel se había pronunciado en el Congreso del SPD en Manheim (1906) contrario a la huelga diciendo que "no provocaremos la revolución con la huelga general». Según Tauber la «prudencia» de Bebel no fue del agrado de Luxemburg quien defen-

18. "En Alemania. Una conferencia de Rosa Luxemburgo", El Socialista, 05-04-1907, p. 3.

19. Analizando la experiencia de la huelga de masas en la revolución rusa, Luxemburg escribió Huelga de masas, partido y sindicato que El Socialista publicó como un folletín. La socialista española Virginia González dijo tras el asesinato de Luxemburg que esa publicación de El Socialista era el único trabajo que conocía de ella. "A la memoria de los buenos. Rosa Luxemburgo y Carlos Liebknecht. Velada en la casa del pueblo", El Socialista, 25-01-1919, p. 1.

20. "En Alemania. Una conferencia de Rosa Luxemburgo", El Socialista, 05-04-1907, p. 3; "En Alemania. Una conferencia de Rosa Luxemburgo (Conclusión)", El Socialista, 12-04-1907, p. 3.

21. "Rosa Luxemburgo", España, 25-04-1918, pp. 10-11. 
dió «hacer estallar la huelga el día en que la guerra fuera declarada» utilizando el ejemplo de los franceses. Pero Tauber quiso resaltar el desconocimiento de la «judía socialista» pues, aunque para ella los franceses fueron a la huelga general cuando se decretó la guerra, Tauber aclaró que cuando una guerra se declarase en Francia, los socialistas se sumarían sin dudarlo a ella. ${ }^{22}$

No obstante, «la batalladora» Luxemburg, como la describió El Socialista, consideraba la huelga un recurso útil y continuó defendiendo su empleo como hizo en el Congreso del SPD en Jena de 1913 cuando atacó a los dirigentes del partido por «su pasividad, su falta de arrestos, de vigor», así lo explicó el periodista Otto Braun, que había estado mandando informaciones sobre el Congreso a El Socialista. ${ }^{23}$

Finalmente, el Congreso del SPD votó en contra de la propuesta de Luxemburg de emplear la huelga general, lo que fue recogido por el diario La Correspondencia de España sin aportar ninguna opinión al respecto: «han triunfado los revisionistas sobre los marxistas puros que dirigen Ledebour, Liebknecht hijo y Rosa Luxemburgo». ${ }^{24}$ La crítica apareció en la Revista Católica de Cuestiones Sociales que sí mostró más entusiasmo ante el triunfo

"colosal" (...) de los revisionistas sobre los radicales, de la derecha sobre la izquierda, de los moderados sobre los violentos. Todas

22. Todas las referencias de este párrafo en: "Carta de Alemania", El Correo Español, 06-101906, pp. 1-2.

23. "En el Congreso de Jena", El Socialista, 1109-1913, p. 3; "Se discute la huelga general", El Socialista, 17-09-1913, p. 1.

24. "Después del Congreso socialista. Opiniones", La Correspondencia de España, 23-091913, p. 2. las mociones revolucionarias presentadas por el Comité femenino, y especialmente por Rosa Luxemburgo, todas, desde la huelga general hasta la del antimilitarismo, han sido rechazadas por imponentes mayorías, por mayorías que se acercan a doscientos votos. $^{25}$

El periodista Manuel Bueno también se mostró contrario al recurso de la huelga general defendido por Luxemburg al preguntarse qué votaría el Congreso del SPD: si sus «vehemencias subversivas» 0 «un criterio de moderación». Bueno recogió, además, las palabras de Eduardo Dato para el que la huelga general era «funesta» y «estéril» hasta el punto de que los socialistas desconfiaban de ella por las represalias que pudiesen ocasionar y la posibilidad de que los Parlamentos decidiesen no legislar a favor del proletariado. En efecto, Dato opinaba que los obreros preferirían antes «la organización y la actividad parlamentaria» que recurrir «al motín, al "sabotage" (sic) y las represalias trágicas». ${ }^{26}$

De igual manera se pronunció la Revista Católica de Cuestiones Sociales al decir que el socialismo alemán consideraba la huelga general «como una catástrofe espeluznante que privaría de pan a todos los militantes del partido, que agotaría las cajas de reserva y propaganda, que aplastaría, literalmente, a las masas, y las dejaría, a la postre, merced del capitalismo». Junto a ello la revista recogió la crítica del delegado Bauer hacia Luxemburg: «Dejemos también charlar (sic) a sus anchas a la ciudadana Rosa Luxemburgo, porque lo que ella diga no tiene importancia. Es

25. "Revista Social Internacional", Revista Católica de Cuestiones Sociales, octubre de 1913, p. 40.

26. "La táctica socialista", Heraldo de Madrid, 05-10-1913, p. 1. 
decir, la tiene contraproducente, pues la más elemental prudencia nos aconsejaría no andar siempre trayendo y llevando la huelga general». ${ }^{27}$

\subsection{Luxemburg a favor del sufragio universal}

Luxemburg, que señalaba al estado capitalista y burgués como negador del voto a las mujeres, ya había destacado la activa y madura participación de ellas en la política alemana a pesar de no tener derecho de voto y, como consecuencia, exclamaba: «hoy millones de mujeres proletarias reclaman desafiantes y llenas de confianza: ¡Queremos el voto!». ${ }^{28}$ El apoyo de Luxemburg al sufragio universal apareció en la prensa madrileña muy relacionado con lo explicado previamente ya que uno de los objetivos que Luxemburg buscaba mediante el empleo de la huelga general era conseguir el sufragio universal femenino en Alemania.

La mayor parte de las noticias relativas a este aspecto fueron críticas no tanto por el objetivo final de conseguir el sufragio universal (lo que fue aceptado por sus compañeros $^{29}$ ), sino por el recurso que Luxemburg propuso para alcanzarlo: la huelga general. En las informaciones sobre diferentes Congresos del SPD se dijo que la propuesta de Luxemburg, la «célebre

27. "Revista Social Internacional", Revista Católica de Cuestiones Sociales, octubre de 1913, pp. 40-47.

28. Luxemburg, R., y Aubet, M. (1983). El pensamiento de Rosa de Luxemburg: antología, Barcelona, Serbal., pp. 281-287.

29. "Planes de ataque y defensa. Después del Congreso de Magdeburgo. Comentarios", La Correspondencia de España, 27-09-1910, p. 2. agitadora ${ }^{30}$ que «llevó todo el peso de la discusión», ${ }^{31}$ de emplear la huelga general para alcanzar el sufragio fue rechazada por el miedo a las repercusiones. Así ocurrió, por ejemplo, en el texto de La Correspondencia de España sobre el Congreso del SPD en Magdeburgo (1910). ${ }^{32}$ Además, la Revista Católica de Cuestiones Sociales, al informar del Congreso en Jena de 1913 y la propuesta de Luxemburg relativa al sufragio universal y cómo conseguirlo, destacó que Bernstein, al que ya se ha nombrado por su posición revisionista, se había pronunciado contrario a la «aventura» de la huelga general, concebida como un ideal romántico, al dudar de las probabilidades de éxito y al no saber cómo acabarla con más de tres millones de proletarios a los que controlar. ${ }^{33}$

En cuanto al congreso en Magdeburgo, el diario católico El Siglo Futuro recogió las palabras del Dr. Max Turmann quien identificó las dos posturas enfrentadas en el socialismo alemán como los revisionistas y los intransigentes o radicales del que formaba parte Luxemburg y que defendía «la huelga general como el medio revolucio-

\section{0. Ídem.}

31. "Revista Social Internacional", Revista Católica de Cuestiones Sociales, octubre de 1913, pp. 40-43

32. "Planes de ataque y defensa. Después del Congreso de Magdeburgo. Comentarios", La Correspondencia de España, 27-09-1910, p. 2. Este año también se celebró el Congreso de la Internacional Socialista en Copenhague y la revista Vida Socialista la identificó como una de las figuras de la internacional y publicó en la portada la primera fotografía de Luxemburg en la prensa madrileña. "Figuras de la Internacional Socialista. Polonia. Rosa Luxemburgo", Vida socialista, 27-11-1910, p. 1.

33. "Revista Social Internacional", Revista Católica de Cuestiones Sociales, octubre de 1913, pp. 40-43. 
nario por excelencia (...) para conquistar el sufragio universal». Turmann comentó que la dirección del partido se negó al uso de «la teoría del carácter anárquico» de la huelga general como medio «para remediar los males sociales» y recordó que para el partido el deber era la «reorganización política y sindical». Además, destacó las palabras de un socialista alemán -Mr. Braun, miembro de la Comisión General de los Sindicatos- para resaltar el desconocimiento de Luxemburg de la realidad. De la misma manera que antes se hizo referencia a que ella no conocía la realidad de Francia, ahora en EI Siglo Futuro se dice que no conoce cómo son los sindicatos y que lo único que quiere es «agitar y provocar». ${ }^{34}$

Finalmente la proposición de Luxemburg de conseguir el sufragio femenino fue rechazada en los Congresos, sobre todo por el medio que propuso para alcanzarlo, por lo que volvió a aparecer en la prensa como una perdedora. ${ }^{35}$

Solamente una información se ha encontrado en la prensa en la que no se hiciera referencia a la forma de conseguir el sufragio. Fue una información que Consuelo Álvarez Pool ${ }^{36}$ escribió para El País sobre el Congreso de la Internacional Socialista en Stuttgart de 1907. Dijo que Luxemburg, junto con Zetkin, la francesa Madeleine Pelletier o la finlandesa Hilja Pärssinen, entre otras, expusieron «con maravillosa elocuencia» la idea de que

34. "El socialismo alemán. El Congreso de Jena", El Siglo Futuro, 03-02-1914, pp. 1-2.

35. "Revista Social Internacional", Revista Católica de Cuestiones Sociales, octubre de 1913, pp. 40, 43-44; "Rosa Luxemburgo", España, 25-041918, pp. 10-11.

36. Escribía con el pseudónimo Violeta para el diario republicano El País. para que un pueblo sea demócrata y justo no puede negar derechos políticos a las mujeres. Además, la periodista quiso destacar que:

contra lo que opinan los ridiculizadores de la mujer política, que nos pintan a estas señoras como unos mamarrachos exentos de todo sentimiento estético, es preciso hacer constar que las congresistas se presentaron en la conferencia, elegantemente ataviadas, aunque con la sencillez y seriedad que el caso requería. ${ }^{37}$

\subsection{Luxemburg contra la querra}

Una cuarta idea que en la primera etapa la prensa madrileña destacó sobre Luxemburg fue su oposición a la guerra, que defendió activamente en mítines y reuniones con consecuencias negativas, ya que fue encarcelada por ello en varias ocasiones como le ocurrió a principios de $1914 .^{38}$

En noviembre de 1912, con la Guerra de los Balcanes en desarrollo, la Internacional Socialista celebró una Reunión Extraordinaria en Bruselas a la que acudió, entre otros, Luxemburg. El Socialista informó que ante el temor de que dicho conflicto desembocara en otro más general, los reunidos se pronunciaron contrarios a la guerra y recogió las palabras de Luxemburg, quien sostuvo que «los acontecimientos actuales no son sino el eslabón de una cadena que el proletariado arrastrará mientras dure el régimen capitalista». ${ }^{39}$ Un mes después la Internacional Socialista celebró un Congreso

37. "El Congreso socialista", El País, 27-081907, p. 3.

38. "Un cuento de Grimm. Rosa Luxemburg", El Socialista, 12-03-2014, pp. 2-3.

39. "La Internacional socialista contra la guerra", El Socialista, 08-11-1912, pp. 1-2. 
Extraordinario para ver formas de oponerse a una posible guerra entre más naciones europeas y El Socialista explicó que a dicho congreso acudió «la simpática y talentosa» Luxemburg y que se firmó un manifiesto por el cual los obreros de todos los países debían trabajar por la paz. ${ }^{40}$

En el Congreso de Jena (1913) Luxemburg también se pronunció contraria a que el partido socialista alemán votara a favor de los créditos de guerra, ya que esa idea, según Luxemburg y en una conferencia en la que los periódicos destacaron que estuvo "graciosísima», «repugna a la masa popular y radical, que protestaba enérgicamente contra los procedimientos burgueses de la fracción socialista del Reichstag» ${ }^{41}$ Además de ser una postura, según la prensa, contraria a la moción adoptada por el Congreso de Dresde de 1903: «se niega a conceder ningún crédito tendente a mantener en el poder a la clase dirigente». ${ }^{42}$

Sin embargo, la proposición de Luxemburg fue rechazada por mayoría. ${ }^{43}$ Otto Braun explicó para El Socialista que tras discutirse el voto a favor de los créditos militares, Luxemburg atacó «furiosamente a los diputados» y concluyó «gritando que entre la burguesía y el Partido Socialista ya no hay obstáculos; sólo existe una lisa llanura, por la que rápidamente caminan los directores socialistas a unirse con la

40. "La Internacional socialista contra la guerra. El Congreso extraordinario de Basilea", El Socialista, 06-12-1912, pp. 1-2.

41. "Un Congreso socialista alemán”, El Correo español, 24-09-1913, p. 1.

42. "El socialismo alemán. El Congreso de Jena", El Siglo Futuro, 03-02-1914, pp. 1-2.

43. "Revista Social Internacional", Revista Católica de Cuestiones Sociales, octubre de 1913, pp. 43-44. burguesía». ${ }^{44}$ De esta forma, el rechazo a la guerra y el veto a los créditos militares sirven a la prensa para recalcar la posición contraria de Luxemburg a un acercamiento con los partidos burgueses.

El pacifismo de Luxemburg fue criticado, además, por La mañana al señalar que los revolucionarios alemanes tenían que convencerse de que «el antipatriotismo es el peor terreno en que puede desenvolverse la acción socialista». ${ }^{45}$

\section{Luxemburg "la rebelde pacifista” (1914-1918)}

La postura en contra de la guerra que Luxemburg había mantenido años antes fue también lo que definió las noticias sobre ella a partir de 1914, pero, a diferencia del periodo anterior, apareció ya como una socialista consolidada con la capacidad de protagonizar noticias en solitario. Así ocurrió, por ejemplo, en el diario El Socialista cuando en marzo de 1914 Luis Araquistáin recogió una información sobre la detención de Luxemburg por haber pronunciado un mitin en contra de la guerra. En el artículo, de más de una columna de extensión (algo que no había ocurrido hasta entonces), alabó su postura pacifista aún cuando la guerra todavía no había empezado, y dijo de Luxemburg que «encarna (...) el espíritu más revolucionario» dentro del socialismo alemán, que alentó al pueblo a no luchar contra sus hermanos franceses y que identificó en la población a la responsable de decretar una guerra y no en el emperador o los gobernantes. Todo ello

44. "La conducta de los diputados", El Socialista, 20-09-1913, p. 2.

45. "Los socialistas alemanes", La Mañana, 1709-1911, p. 1. 
contribuiría a que fuese una guerra democrática y no absolutista. ${ }^{46}$

Pero la guerra estalló y Alemania participó en ella. Luxemburg, en el folleto que escribió en prisión y firmó como Junius, consideró la contienda mundial como una «catástrofe» y la decisión de los socialistas alemanes de votar los créditos de guerra una «capitulación (...). La caída más profunda, el desmoronamiento más gigantesco». ${ }^{47}$

A la hora de analizar las noticias sobre ella y su posición en contra de la guerra en los mismos años en los que tuvo lugar conviene hacer una aclaración: aunque España no participó en la Primera Guerra Mundial, la sociedad, los políticos y los periódicos sí se posicionaron a favor o bien de los Aliados o bien de los Imperios Centrales, ${ }^{48}$ por lo que la imagen que dieron los periódicos de Luxemburg (alemana) estuvo influida por la posición que tomaron respecto a la contienda mundial. Así, la prensa aliadófila y la prensa germanófila españolas la describieron de diferente forma.

\section{4.l. Luxemburg en la prensa aliadófila madrileña}

Las apariciones de Luxemburg en la prensa aliadófila madrileña fueron, en general, para alabarla o para atacar a los alemanes o, de forma más específica, al sector de los alemanes y de los socialistas

46. "Un cuento de Grimm. Rosa Luxemburg", El Socialista, 12-03-2014, pp. 2-3.

47. Luxemburg, R. (2006) La crisis de la socialdemocracia, Madrid, Fundación de Estudios Socialistas Federico Engels.

48. Fuentes Codera, M. (2014) España en la Primera Guerra Mundial. Una movilización cultural, Madrid, Akal. alemanes de los que Luxemburg no formaba parte, es decir, a los que habían apoyado la guerra.

La postura antimilitarista de Luxemburg fue acogida con buenas palabras por esta prensa. Así ocurrió en la revista semanal Acción Socialista que destacó cómo Luxemburg se había posicionado "contra la corriente, contra las voces de los vividores de la guerra, contra el inculto populacho militarista» y con "voz enérgica» y «augusta» destacó los beneficios de la paz. ${ }^{49}$ Misma posición tomó un editorial del diario republicano El País alabando el surgimiento del verdadero socialismo alemán que rompía «la cerrazón del horizonte» con «una mujer, la audaz Rosa Luxemburgo, [que] es todo un hombre entre aquellos lacayos del militarismo».50

Por su parte, la revista La Lectura recogió un artículo del socialista francés Paul Louis en el que dijo que en Alemania «Liebknecht, Mehring, Rosa Luxembourg, Clara Zetkin, han luchado contra el derrumbamiento actual». ${ }^{51} \mathrm{Y}$ el Heraldo de Madrid la describió como una socialista rebelde, ${ }^{52}$ aunque viniendo de un periódico aliado, ser rebelde no era negativo cuando los socialistas habían apoyado la guerra.

Eduardo Torralba Beci, fundador del Partido Comunista de España, escribió en la revista ilustrada Acción socialista el primer

49. “¿Fusilado?”, Acción socialista, 22-08-1914, p. 7.

50. “El socialismo alemán”, El País, 07-12-1914, p. 1.

51. "Francesas", La Lectura, enero de 1915, p. 243; Este artículo también apareció en la revista conservadora Nuestro Tiempo: "La actitud de los socialistas alemanes", Nuestro tiempo, abril de 1915, p. 116.

52. "Francia y la guerra. La paz lejana...", Heraldo de Madrid, 02-12-1916, p. 1. 
gran artículo sobre Luxemburg junto con una imagen de ella en la portada, que apareció en agosto de 1915. Torralba Beci la describió como una famosa escritora y propagandista alemana que estaba encarcelada por hacer campaña pacifista. Era «la más rebelde que ha tenido el Socialismo alemán», "una nota aparentemente discordante». Temida por sus compañeros con unos «discursos formidables» y que se mantuvo «erguida, inflexible». Aunque sin gentileza y «casi deforme (...) en la tribuna se transforma (...) Parece una mujer de alta estatura, de formas proporcionadas, simpática, cuando la tribuna oculta a los ojos de los que la contemplan el defecto de sus piernas cortitas». De voz «metálica» que «desgarra los oídos», conseguía transformarse y conquistar a las masas. Destacó también que «en la presente crisis del Socialismo alemán, como no podía ser menos, Rosa Luxemburgo está entre los buenos» y, junto con Liebknecht, había recogido «la roja bandera socialista que otros habían dejado caer» ondeándola con «valentía», «honradez»y "grandeza del alma (...) por encima de la soberbia odiosa del imperialismo». ${ }^{53}$

De la misma manera la describió el periodista José L. Martínez Ponce en la revista España, "el medio de prensa de los más señeros intelectuales españoles del momento»,54 cuando criticó la postura tomada por el socialismo alemán ante la guerra y destacó la posición de Luxemburg describiéndola como un «espíritu fuerte, revolucionaria consecuente, "perturbadora" de la quietud amodorrada del partido en tiempo de paz, vindicadora de

53. "Rosa Luxemburgo", Acción socialista, 2208-1915, pp. 1-3.

54. García Sanz, F. (2014) España en la Gran Guerra: espías diplomáticos y traficantes. Barcelona, Galaxia Gutenberg., p. 56. la tradición revolucionaria en el momento de peligro» que había recogido la bandera roja «abandonada por los jefes». 55

Los socialistas españoles alabaron la figura de Luxemburg e incluso era ensalzada en mítines públicos. ${ }^{56}$ De forma más personalizada la elogió el socialista Julio Álvarez del Vayo que la había conocido y escribió para España sus impresiones sobre ella. ${ }^{57}$ La describió como "una mujer menuda y contrahecha» que despertaba «animadversión» entre sus compañeros de partido, que cuando hablaba en la tribuna, subida a su banqueta, acallaba a sus contrarios, que se "había dedicado al estudio y la propaganda de la acción directa de masas» y que fue autora de un folleto publicado clandestinamente que, con el pseudónimo Junius, pasaba de mano en mano, en el que se explicaba a dónde la autora quería llevar al pueblo alemán. Álvarez del Vayo destacó cómo en el Congreso de Jena de 1913 Luxemburg luchó por el sufragio universal, pero señaló que el verdadero objetivo era «que la Social-democracia sacudiese su poltronería ideológica» y comenzara a actuar. Quiso destacar también Álvarez del Vayo la acción del grupo de Luxemburg, -los minoritarios del partido socialista alemán-, contraria a la guerra: «algún día (...) se hará más justicia a este grupo». Y cómo los obreros alemanes fantaseaban: «iSi estuviera en el Reichstag, si la Rosa fuera hombre!». ${ }^{58}$

55. "El socialismo ante la guerra", España, 2704-1916, pp. 11-12.

56. "El mitin de las izquierdas. Los discursos", $E l$ Heraldo Militar, 29-05-1917, p. 2.

57. También publicó este artículo tras la muerte de Luxemburg y Liebknecht en enero de 1919: "Recuerdo de Rosa Luxemburgo", El País, 2101-1919, pp. 1-2.

58. "Rosa Luxemburgo", España, 25-04-1918, pp. 10-11. 
El apoyo de la mayor parte de los socialistas alemanes a la contienda sirvió a los periódicos también para destacar la división cada vez más profunda entre los dos grupos del socialismo alemán: los intransigentes y los revisionistas. La diferencia entre ambos era clara: los primeros quieren la república social en la que todos los poderes recaigan en unos representantes del pueblo, mientras que los segundos prefieren una república burguesa. ${ }^{59}$ Manuel G. Morente en la revista España -cuyo director era el socialista Araquistáin- defendió a los intransigentes al decir que "han empezado a oírse voces discordantes en el concierto patriótico. Rosa Luxemburg, la rosa roja, y Carlos Liebknecht, el niño terrible del partido, se han alzado contra las decisiones tomadas». A pesar de ello, añadía que el socialismo alemán seguía tendiendo hacia el revisionismo ${ }^{60}$ con unos «cabecillas (...) a los que la guerra ha vuelto completamente locos».61 A este respecto, a la prensa madrileña llegaron los ecos de un artículo de Luxemburg en el que se quejaba de la situación en la que se encontraba el socialismo alemán y en el que decía que «el veneno patriótico sigue ejerciendo en los obreros alemanes una acción violenta». ${ }^{62}$

59. "La revolución en Alemania", España, 1411-1918, p. 8.

60. "El socialismo alemán y la guerra”, España, 19-03-1915, p. 2.

61. "Alemania por dentro. Manifiesto socialista en pro de la paz", La Correspondencia de España, 10-04-1915, p. 1; "El socialismo y la guerra. Manifiesto de los socialistas alemanes a favor de la paz”, La Época, 10-04-1915, p. 2.

62. "Rosa Luxemburgo", El País, 11-01-1915, p. 3. Con las mismas palabras también en: "Rosa Luxemburgo. Una lamentación”, La Correspondencia de España, 11-01-1915, p. 2.
Y es que el papel de los socialistas alemanes con respecto a la guerra sirvió a los periódicos para alabar a Luxemburg y despreciar a los otros. El sacerdote anticlerical Segismundo Pey Ordeix en la revista satírica El Motín y ante una noticia (falsa) del fusilamiento de Luxemburg y Liebknecht, ironizó sobre las muertes de la guerra entre los "cobardes que se dejan matar como borregos» y «los conscientes: los que mueren por no matar, en manos de los que matan por no morir». ${ }^{63}$

Como ejemplo de la división existente entre los socialistas alemanes sirva un artículo en el que se explicaba que por Alemania se vendía una caricatura que presentaba a Schoeplfin, Philipp Scheidemann y Friedrich Ebert, del grupo socialista mayoritario, conversando con oficiales del Estado mayor, mientras Luxemburg y Zetkin aparecían recluidas en prisión. A lo que Schoeplfin añadió: "No es un deshonor para mi verme representado en un grabado en compañía de oficiales que todos los días luchan con la muerte; pero me sería muy desagradable, por el contrario, verme unido en un dibujo a ciertos jefes de nuestra oposición socialista». ${ }^{64}$

Los periódicos también recogieron informaciones sobre Luxemburg en las que en realidad se criticaba al Gobierno alemán. Así ocurrió con el periódico La Correspondencia de España que resaltó el proceso contra «la famosa escritora y oradora socialista» en el que Luxemburg

63. "Los inocentes culpables", El Motín, 03-091914, p. 4.

64. "Los socialistas alemanes.- Viaje y caricatura comentados", La Época, 01-12-1915, p. 2. A pesar de que La Época era un diario conservador, órgano de Eduardo Dato, recibió financiación de los países aliados. En: Cruz Seoane, M. y Sáiz, M. D. (1998) Historia del periodismo..., pp. 8890 у $218-221$. 
habló de los malos tratos que sufrían los soldados dentro del ejército alemán. ${ }^{65}$ Por su parte, Heraldo de Madrid criticó que «la valiente socialista» tuviera que entrar en prisión por su propaganda antimilitarista como si ya el Gobierno alemán no permitiera tener opiniones. ${ }^{66}$

\subsection{Luxemburg en la prensa germanófila madrileña}

Las apariciones de Luxemburg en la prensa germanófila son menores $y$, al contrario que en el caso anterior, no son para hablar bien de ella. La revista conservadora Nuestro Tiempo la identificó como una radical, ${ }^{67}$ Antonio Azpeitua ${ }^{68}$ la describió en $A B C$ como exaltada ${ }^{69}$ y Luis de Castro, llamándola "Rosina" y describiéndola como "socialista y rubia", destacó el papel de terrorista y antimilitarista de Luxemburg en el diario católico y carlista El Correo español. Añadió, además, que era una "sacerdotisa de un rito sin fieles» que predicaba alejada de la realidad y alertó de sus intentos porque «ya lo dijo Ibsen: "las mujeres nos truecan los destinos y nos arrebatan las victorias"». ${ }^{70}$

También se usaron informaciones sobre ella para atacar a sus enemigos en la gue-

65. "Aplazamiento comentado. Los mil trece testigos de Rosa Luxemburgo. ¿Hasta cuándo?”, $L a$ Correspondencia de España, 07-07-1914, p. 2.

66. Heraldo de Madrid, 16-01-1915, p. 1. Acompaña la información un retrato de Luxemburg.

67. "La posición actual del socialismo", Nuestro tiempo, junio de 1917, pp. 123-125.

68. Pseudónimo del periodista Javier Bueno.

69. "Los trabajos de paz. Radiogramas de ABC. La actitud de los rusos en la negociación", $A B C$, 14-01-1918, p. 17.

70. "Rosa Luxemburgo", El correo español, 1407-1916, p. 2. rra. Así lo hizo el católico El Correo Español utilizando su nombre para arremeter contra los aliados. Para ello recogió las crónicas de la guerra de Vicente Vera publicadas en El Imparcial. El diario católico las identificó como «la verdad acerca de la guerra. Un testimonio de un corresponsal serio y veraz» al no haber sido sometida la información a la censura inglesa. Según este periodista, las informaciones sobre el asesinato de Luxemburg y Liebknecht fueron invenciones de los ingleses y recalcó cómo Liebknecht estaba luchando y cómo muchos socialistas alemanes se habían sumado voluntariamente a la guerra. ${ }^{71}$

\subsection{La prensa ante su encarcelamiento}

El hecho de mantener Luxemburg una posición activa contra la guerra en uno de los países que decidió intervenir en ella hizo que adquiriese más protagonismo. Conforme van pasando los meses, Luxemburg siguió desarrollando su propaganda pacifista, lo que la llevó a la cárcel. Principalmente fueron los diarios aliadófilos, liberales y socialistas (Acción socialista, ${ }^{72}$ El Imparcial, ${ }^{73}$ El Liberal, ${ }^{74}$ El

71. "La guerra vista desde Berlín", El Imparcial, 24-08-1914, p. 1; "La guerra vista desde Berlín", El Correo español, 25-08-1914, p. 1.

72. "Rosa Luxemburgo", Acción socialista, 2208-1915, p. 1.

73. "Detención de socialistas alemanes", El Imparcial, 23-07-1915, p. 2; "La propaganda pacifista”, El Imparcial, 22-11-1915, p. 1.

74. "Rosa Luxemburgo, presa", El Liberal, 1501-1915, p. 2; "Por telégrafo sin hilos", El Liberal, 13-03-1915, p. 1; "De Francia. A las 6 de la tarde", El Liberal, 26-04-1915, p. 1; "Prisión de Rosa Luxemburg”, El Liberal, 23-07-1915, p. 2. 
País, ${ }^{75}$ El Radical, ${ }^{76}$ El Socialista ${ }^{77}$ Heraldo de Madrid, ${ }^{78}$ La Correspondencia de España ${ }^{79}$ y $L a E_{\text {poca }}{ }^{80}$ ) los que recogieron las noticias de su detención por motivos pacifistas. También fueron los que destacaron cómo el Gobierno la mantenía en prisión a pesar de su mal estado de salud. ${ }^{81}$ Es decir, los periódicos aliadófilos usaron los encarcelamientos de Luxemburg para generar una imagen negativa del Gobierno alemán. El Socialista, por ejemplo, escribió que «el militarismo alemán se ha embarcado en una mala aven-

75. "Alemania y los yanquis.- Una indemnización”, El País, 27-04-1915, p. 2.

76. "Rosa Luxemburgo, libertada", El Radical, 03-03-1916, p. 3.

77. "La propagandista, condenada. Rosa Luxemburgo y el antimilitarismo", El Socialista, 25-02-1914, p. 2; "Un cuento de Grimm. Rosa Luxemburg", El Socialista, 12-03-2014, pp. 2-3; "De Oportunidad. Contra Rosa Luxemburg", El Socialista, 04-07-1914, p. 1; "El proceso contra Rosa Luxemburgo", El Socialista, 04-07-1914, p. 1.

78. Heraldo de Madrid, 16-01-1915, p. 1.

79. "Últimos radiogramas. De Inglaterra y Francia”, La Correspondencia de España, 2302-1915, p. 2; "Detención de Rosa Luxemburgo. Por hablar...", La Correspondencia de España, 25-02-1915, p. 1; "Servicio de radiogramas. De Inglaterra y Francia", La Correspondencia de España, 26-04-1915, p. 2; "Rosa Luxemburgo. Ha ingresado en la cárcel", La Correspondencia de España, 23-07-1915, p. 2.

80. "Prisión de Rosa Luxemburgo", La Época, 14-01-1915, p. 2; "Rosa Luxemburgo, detenida", La Época, 23-02-1915, p. 2. "La socialista alemana Rosa Luxemburgo, detenida”, La Época, 22-07-1915, p. 2.

81. "Servicio de Radiogramas. De Inglaterra y Francia”, La Correspondencia de España, 09-051915, p. 3; "A las 6 de la tarde", El Liberal, 0905-1915, p. 2; "Rosa Luxemburgo, encarcelada", La Época, 09-05-1915, p. 2. tura, intentando perseguir a la gran socialista Rosa Luxemburgo».82

En algunos artículos incluso se habló de la «manera villana» en que era tratada Luxemburg en prisión. ${ }^{83}$ Así lo hizo Álvarez del Vayo cuando criticó en El Liberal el trato que se le dio a Franz Mehring y Luxemburg en la cárcel en 1916. De ella destacó que sin motivo legal alguno y estando enferma la llevaron una noche a prisión, le prohibieron las visitas, incluso la de su médico, le prohibieron también los periódicos, los libros y tuvo una escasa alimentación «que solo a la estupenda energía de esa mujer, cien veces admirable, cabe atribuir el que haya podido resistirlo». ${ }^{84}$

Solamente tres referencias se han encontrado a su encarcelamiento en los diarios germanófilos. En $A B C$ «porque abogó contra la guerra ${ }^{85}$ y otro artículo en el que no se especificaron los motivos de su detención. ${ }^{86}$ La tercera noticia la escribió Luis de Castro en El Correo Español explicando que su detención se debió a las «catilinarias antimilitaristas» que empleaba en su propaganda pacifista. ${ }^{87}$

82. "El proceso contra Rosa Luxemburgo", El Socialista, 05-07-1914, p. 1.

83. “Karl Liebknecht”, España, 02-11-1916, p. 5. 84. "De Alemania. El terror blanco", El Liberal, 27-11-1916, p. 2.

85. En este artículo se identifica a Luxemburg con Luise Michel. " $A B C$ En Ginebra. Viajeros ilustres", $A B C, 10-04-1915$, p. 7.

86. "Detención de una socialista", $A B C, 14-07-$ 1916, p. 13

87. "Rosa Luxemburgo", El correo español, 1407-1916, p. 2. 


\section{Tercera etapa, Luxemburg "la mártir" (1918-1919)}

Este periodo de ocho meses es en el que más noticias hay a pesar de que Luxemburg no salió de prisión hasta noviembre de 1918, por lo que en realidad solo fueron tres los meses en los que Luxemburg pudo desarrollar una intensa actividad política. Aún así, la mayor parte de las noticias no hicieron referencia a su acción, sino que es una vez asesinada cuando los periódicos publicaron más noticias sobre ella identificándola como una mártir.

\section{5.l. El pacifismo de Luxemburg}

Los periódicos volvieron a señalar el pacifismo de Luxemburg como el comportamiento modélico que debían seguir los socialistas de todos los países ${ }^{88}$ y llamaron la atención sobre lo contradictorio de que se hubiera perseguido a Luxemburg por sustentar un proyecto que en esos momentos los gobernantes alemanes se empeñaban en alcanzar: la paz. ${ }^{89}$ En su lucha por ese fin, Torralba Beci la identificó como «la eterna rebelde»90 y El País recalcó que el grupo minoritario al que pertenecía Luxemburg era «lo único digno, decente, universalmente admirado» que había en Alemania. ${ }^{91}$

Pero no todas las noticias en las que apareció fueron positivas. El Heraldo de Ma-

88. "La Guerra", España, 22-08-1918, p. 9; "Cartas del frente", España, 29-08-1918, p. 14.

89. "Karl Liebknecht”, España, 10-10-1918, p. 10.

90. “Cuatro años después”, España, 30-10-1918, p. 16.

91. "La revolución en Prusia. Enseñanzas compartidas”, El País, 15-01-1919, p. 1. drid, en un artículo de irónico titular "deidades del cielo", criticó el sistema político que «la vitanda» y «sectaria» Luxemburg quería crear por injusto y por querer imponer un imperialismo. Fue con motivo de la crítica de Luxemburg a la Sociedad de Naciones que era, según ella:

el baluarte que levanta para su defensa el sistema de expoliación del obrero que se llama Estado burgués. (...) Contra la arcaica estructura del Poder público hay que echar (...) no rebaños de hombres uniformados, sino masas dispersas, que formen núcleos invencibles cuando suene la hora trágica para arrollar a los detentadores del pan del proletariado.

Para Luxemburg, de ese modo se construirá un nuevo mundo sobre «la base de la justicia distributiva» en el que los países comunistas, espartaquistas o bolcheviquistas formarían un solo Estado que haría caer la Liga de las Naciones, según explicó el Heraldo de Madrid. Pero el periódico criticó que ese gobierno sería un imperialismo disfrazado, a lo que Luxemburg replicó: "pero este imperialismo redimirá a los hombres de la servidumbre, mientras el otro le condenaba a ella». ${ }^{92}$

\subsection{Detalles de su vida}

Empezaron a aparecer en esta etapa noticias que detallaron aspectos de la vida de Luxemburg que no habían salido en la prensa hasta entonces. El periódico El Fígaro señaló su procedencia polaca, pero que fue en Alemania donde desarroIló la actividad política con un temperamento «rebelde, fogoso», con «campañas llenas de violencia» y siendo escuchada

92. "Las figuras del retablo. Las deidades del cielo", Heraldo de Madrid, 18-12-1918, p. 1. 
«Con veneración» por el público. ${ }^{93}$ Varios periódicos hicieron hincapié en su papel como editora y directora de periódicos. ${ }^{94}$ El menchevique Nikolái Tasin ${ }^{95}$ destacó, además, su fuerza a la hora de pronunciar los discursos y su papel teórico con artículos de estilo «vigoroso y brillante». A este respecto, escribió: "ha rivalizado con los mejores teóricos del partido y sus trabajos sobre economía política son apreciados aun por los economistas burgueses». ${ }^{96}$

Los periódicos hicieron referencia también a sus años en prisión. Para El Fígaro, Luxemburg se pronunció «valientemente» contra la guerra y fue encarcelada por ello, «parecía que el Gobierno alemán estaba dispuesto a deshacerse de ella a cualquier precio». ${ }^{97}$ Tasin explicó que había sido condenada a cárcel por la «violencia [y la] intransigencia» empleada en su acción convirtiéndose la cárcel en «un segundo hogar» para ella. ${ }^{98}$ Algo similar dijo Azpeitua quien recalcó en $A B C$ los diez años que pasó en la cárcel y añadió: «según parece, esas temporadas pasadas en la prisión son las mejores de su vida,

93. "Rosa Luxemburgo en libertad", El Fígaro, 12-11-1918, p. 10.

94. "El grupo Spartacus", España, 19-12-1918, pp. 6-7; "Un periódico del grupo 'Spartacus'”, El Sol, 20-11-1918, p. 5; “'La Bandera Roja”", La Nación, 20-11-1918, p. 7.

95. Zoffmann Rodríguez, A. (2018) "El menchevique madrileño: Nikolái Tasin y la revolución rusa en España”, EBRE 38. Revista Internacional de la Guerra Civil 1936-1939, núm. 8, pp. 25-51.

96. "Política internacional. La socialdemocracia alemana. Siluetas de los jefes (Conclusión)", El Sol, 06-01-1919, p. 2.

97. "Rosa Luxemburgo en libertad", El Fígaro, 12-11-1918, p. 10.

98. "Política internacional. La socialdemocracia alemana. Siluetas de los jefes (Conclusión)", El Sol, 06-01-1919, p. 2. porque es una revolucionaria que no gusta de quehaceres domésticos y la Administración de prisiones se cuidaba de barrerle la celda y de guisarle la comida». ${ }^{99}$

Firmado por Maese Pedro, el Heraldo de Madrid, en el ya mencionado artículo que la consideraba, en tono irónico, una deidad del cielo, habló de ella en un aspecto que casi no había sido desarrollado hasta ahora: su papel para la organización de crímenes políticos: "está su historia llena de sangrientas páginas». ${ }^{100}$ Es conveniente preguntarse por qué el Heraldo de Madrid, que tan bien había hablado de Luxemburg en los primeros años de la Guerra Mundial, muestra ahora su lado negativo. La respuesta se encuentra en las revoluciones rusas y alemanas y su inevitable relación pues, aunque las revoluciones rusas tuvieron lugar en 1917, no es hasta finales de 1918 cuando los periódicos asociaron a Luxemburg con el movimiento maximalista ruso. Fue entonces cuando los periódicos recogieron más noticias sobre las consecuencias negativas de las políticas de los bolcheviques (quienes, por cierto, sacaron a Rusia de la contienda mundial contrariando a los Aliados y en beneficio de Alemania). El que los periódicos considerasen el bolcheviquismo de forma negativa y que viesen similitudes entre las dos revoluciones, hace que la negatividad hacia los rusos se traspase a los espartaquistas y con ello a Luxemburg, incluso en periódicos que antes habían hablado bien de ella. Mucho más cuando en una época de debilidad económica, política y social en España, el desarrollo de movimientos revolucionarios en Europa llevó a los periódicos a desta-

99. "La historia de la revolución alemana. XI", $A B C, 05-01-1919$, p. 4.

100. "Las figuras del retablo. Las deidades del cielo", Heraldo de Madrid, 18-12-1918, p. 1. 
car sus aspectos negativos en un intento de influir en la opinión pública y que no se produjese un movimiento similar en España. De esta forma, Luxemburg fue identificada como bolchevique ${ }^{101}$ y La Correspondencia de España, que tan bien había hablado de ella, la consideró una extremista. ${ }^{102}$

\subsection{Asesinato y reacciones de personalidades españolas}

Las noticias sobre el asesinato de Luxemburg fueron recogidas en la prensa madrileña de forma dispersa, primero en forma de rumor y luego como noticia confirmada entre los días 15 y 17 de enero de 1919 señalando como los causantes de su muerte a las turbas enfurecidas. Es decir, en la prensa madrileña se transmitió la imagen de que Luxemburg y las propuestas que hacía eran tan odiadas por el pueblo que este, aprovechando un traslado de la espartaquista a la cárcel, se abalanzó sobre ella y la linchó hasta matarla, arrojando posteriormente su cadáver a un canal.

Muchos periódicos madrileños se negaron a creer las informaciones y sostenían que sería un punto negro no solo en la historia de Alemania, sino en la historia de la humanidad al destacar a Luxemburg y Liebknecht -líder espartaquista que también fue asesinado- como grandes personalidades. Además, algunos periódi-

101. "Hacia otra Alemania", España, 24-101918, p. 5; "La revolución en Alemania", España, 14-11-1918, p. 8; "Política Exterior", El Día 21-11-1918, p. 2; "Política Internacional. La lucha del bolcheviquismo en Berlín", El Sol, 2911-1918, p. 1.

102. "Los extremistas alemanes", La Correspondencia de España, 23-12-1918, p. 1. cos cuestionaron la versión oficial de las muertes de estos. ${ }^{103}$ Incluso hubo quien señaló que los asesinatos habían sido hechos por "secuaces de los Scheidemann y los Noske». ${ }^{104}$ Pero solo fue El Socialista quien informó (en marzo) del verdadero relato de los hechos en el que no intervino la muchedumbre y sí los militares. ${ }^{105}$ Hasta entonces la versión que utilizaron los periódicos madrileños fue la oficial alemana: que la población los mató. Y en base a ello muchas publicaciones reaccionaron.

Por ello, El Socialista decidió a principios de febrero publicar el programa de los Espartacos con la intención de que, al divulgar sus «hermosos propósitos (...), mayor será la repulsión» que causarían los asesinatos. ${ }^{106}$ Esta publicación tuvo su crítica por parte del El Imparcial que reprochó el programa al señalar que los espartaquistas «no dejan nada en pie. Nada que no sea su soberana voluntad. Nada que no sea su propia tiranía», porque su programa, como el de los bolcheviques, es «absurdo (...) antidemocrático y antiigualitario (...) y no puede predominar más que en el re-

103. "ABC en Alemania. Apuntes para la historia de la revolución alemana. XXXI", $A B C, 18-02-$ 1919, pp. 3-4; "Los grandes asesinatos políticos. Cómo murió Carlos Liebknecht. Un periodista francés cuenta el drama de la muerte del jefe espartaquista", El Sol, 15-05-1919, p. 1; "El asesinato de Liebknecht", El Socialista, 20-05-1919, p. 2; "Mártires de la Revolución. Liebknecht y Rosa Luxemburgo", El País, 19-01-1919, p. 1.

104. "Documento histórico. El Manifiesto del grupo "Espartaco", El Socialista, 18-01-1919, p. 2.

105. "Una conversación con Eduardo Bernstein. ¿Qué quiere la nueva Alemania?”, El Socialista, 27-02-1919, p. 1; "Cómo se asesinó a Liebknecht y a Rosa Luxemburgo", El Socialista, 18-031919, p. 2.

106. "Programa del grupo 'Espartaco"”, El Socialista, 01-02-1919, p. 1. 
cinto de un manicomio». ${ }^{107}$ El Socialista no se quedó callado ante esa reacción y, con la firma de Maligno, se lamentó en tono irónico que «al reproducirlo (...) no hemos tenido en cuenta que desagradaría a la prensa burguesa», pues su única intención, añadía, era «enseñar el camino a los españoles explotados, víctimas del capitalismo español, de los deplorables políticos como el dueño de El Imparcial y de la prensa como El Imparcial»». ${ }^{108}$

La crítica de El Imparcial fue una de las dos noticias negativas que en la prensa madrileña se encontró hacia Luxemburg tras su muerte. La segunda apareció en el periódico conservador La Acción, órgano de Maura, que consideró a Luxemburg y Liebknecht «víctimas de su propia obra». ${ }^{109}$

El resto de las referencias hacia Luxemburg fueron para reconocer su papel dentro del socialismo alemán. Así se pronunciaron personalidades de la escena política e intelectual española, sobre todo del socialismo (e incluso con alguna poesía en honor de Luxemburg), ${ }^{110}$ como lo hicieron Álvarez del Vayo, Araquistáin, Manuel Pedroso o Gabriel Alomar, algunos de los cuales habían llegado a conocerla.

Álvarez del Vayo se negó a creer los detalles de la muerte de Luxemburg que

107. "No queda nada en pie. Excelencias del grupo Espartaquista", El Imparcial, 03-02-1919, p. 1. 108. "Lo sentimos; pero...", El Socialista, 0502-1919, p. 1.

109. "Prensa de Madrid", El Día, 19-01-1919, p. 3.

110. "Una poesía. A Rosa Luxemburgo. Responso", El País, 26-01-1919, p. 2; "A Rosa Luxemburgo en el primer aniversario de su inmolación. Prosa rimada", El País, 14-06-1919, p. 1; "A la memoria de Rosa Luxemburgo", El Socialista, 27-02-1919, p. 2; "Para una tumba", El Socialista, 25-01-1919, p. 2. atribuía más a la morbosa imaginación «del sensacionalismo macabro» que a la realidad. Destacó cómo Luxemburg había convertido la causa del pueblo alemán, que no era el suyo, en su causa y cómo había combatido "con persistencia admirable antes, durante y después de la guerra» contra el «régimen de opresión, del prusianismo bárbaro y grosero». Por ello, añadió, con el asesinato de Luxemburg «caerá inevitablemente sobre la Alemania de ahora el baldón de que bajo sus albores haya ocurrido acto semejante». ${ }^{111}$

Araquistáin los consideró como unos crímenes repulsivos sin explicación ejecutada por «una muchedumbre de esclavos a quienes estas dos desdichadas criaturas habían querido hacer seres libres. Hay en esas muertes algo de la tragedia del Cristo que sucumbe a manos de aquellos que justamente quería redimir». Agregó que los gobernantes revolucionarios pudieron haberlos llevado ante la justicia, pero «han preferido entregarlos a un pelotón de soldados irresponsables y a una multitud irritada» por lo que no sirve de nada que se lamenten. Destacó la pobreza moral que tendría el mundo con sus asesinatos y señaló también el papel intelectual de Luxemburg: "pocos hombres habían ahondado tanto como ella en el océano marxista». ${ }^{112}$

El Liberal se negó a creer las primeras informaciones y por eso «dimos (...) la noticia escueta y con la esperanza de desmentirla» y añadió que su muerte sería una «mancha eterna (...) en la historia de la Humanidad». Identificó a Luxemburg y

111. "Se confirma oficialmente la muerte de Liebknecht y de Rosa Luxemburgo", El Sol, 18-011919, p. 1.

112. "Liebknecht y Rosa Luxemburgo. Dos grandes pérdidas morales", El Fígaro, 19-01-1919, p. 3. 
a Liebknecht como idealistas y utopistas, como "claras antorchas de una luz nueva y portaestandartes de un ideal sagrado» que quizás iban «demasiado allá en su protesta». Criticó a los gobernantes alemanes por sus «voluntades arbitrarias y poderes anacrónicos que oprimían con mano de hierro al país» y porque «la mano sangrienta y desalmada (...) ha buscado víctimas entre los elementos enemigos del imperialismo y de la guerra (...) y se ha dejado caer ciega, brutal, sobre las cabezas del apóstol del maximalismo y de la iluminada propagandista de las reivindicaciones populares». ${ }^{113}$

El País los consideró mártires de la revolución y sintió pena e ira al saber cómo «la soldadesca ha asesinado al hombre [y] la patulea, la piara, la morralla, ha asesinado a la mujer». Destacó el diario cómo la guerra había convertido en idiota a la humanidad, haciéndola retroceder hasta el punto de cometer una animalidad. El kaiserismo, continuó El País, no solamente estaba en la figura del Guillermo II, «sino en las entrañas del pueblo», siendo «la falsa República (...) peor que el Imperio». El periódico dijo con respecto a Luxemburgo que «el crimen cometido con una mujer, débil por el sexo, sagrada por estar presa, es todavía más repugnante». ${ }^{114}$

Manuel Pedroso recordó en España cómo había conocido a la «pequeña, inquieta, nerviosa» de pelos grises y bondad en el rostro Luxemburg en el Congreso de Jena de 1911 y cómo ella estaba desilusionada por el camino que estaba tomando el

113. "Los jefes del grupo "Spartacus". Liebknecht y Rosa Luxemburgo", El Liberal, 18-011919, p. 1.

114. "Mártires de la Revolución. Liebknecht y Rosa Luxemburgo", El País, 19-01-1919, p. 1. socialismo alemán. Destacó que la revolución, la misma que la había liberado de la cárcel, la había matado y cómo Rosa «con exquisitez femenina» se desmayó ante «la repugnancia del espectáculo de que iba a ser víctima». Por último, los denominó, a ella y a Liebknecht, héroes que habían sido sacrificados por un ideal. ${ }^{115}$

Gabriel Alomar escribió que las muertes suponían la derrota de Alemania y se irritaba al pensar en la escena del asesinato de Luxemburgo quien era, según él:

una mujer (...) con un prestigio varonilmente ganado en la más airosa de las luchas contra el militarismo cesáreo; una mujer cuyo martirio será en el porvenir una ignominia para el pueblo que en masa la consumó y un nombre en la serie de los que han rescatado con su sacrificio la vida animal y materialista de las multitudes. ${ }^{116}$

Y Alomar se preguntó: «¿quién recogerá la bandera de Liebknecht, más roja hoy con la sangre del campeón y con la de esa mujer heroica?». Añadió que «el rebelionismo épicamente suicida de Carlos Liebknecht y Rosa Luxemburgo es más eficaz para rebautizar el mundo que toda la sangre derramada en las batallas de esa guerra cuyos fines espirituales están desvirtuándose». ${ }^{117}$

El 24 de enero de 1919 la institución Escuela Nueva organizó en la Casa del Pueblo de Madrid «una gran velada en honor de los heroicos socialistas alemanes

115. "Una infamia colectiva. Liebknecht y Rosa Luxemburgo", España, 23-01-1919, pp. 8-9.

116. "La deshonra del pueblo alemán", El País, 26-01-1919, p. 2. También publicado en: "Rosa Luxemburgo y Liebknecht. La deshonra del pueblo alemán”, El Motín, 30-01-1919, pp. 1-2; “La deshonra del pueblo alemán”, El Socialista, 2501-1919, pp. 1-2.

117. Ídem. 
Rosa Luxemburgo y Carlos Liebknecht» ${ }^{118}$ "asesinados vilmente en Berlín». ${ }^{119}$ Una velada de la que La Acción quiso destacar las contradicciones al no saberse bien las causas de las muertes. Manuel Núñez de Arenas, que presidía el acto, aclaró el objeto de la velada y pidió a los asistentes que se abstuvieran de provocar altercados al finalizarla. De la Asociación de Estudiantes Socialistas intervinieron Ramón Merino Gracia y José Antonio Balbontín, quienes alabaron las figuras de los dos espartaquistas identificando en ellos «los principios absolutos del socialismo integral» y destacando cómo fueron perseguidos por oponerse a la guerra. Virginia González, de la Agrupación Femenina Socialista de Madrid, se lamentó de que en España no hubieran mujeres «tan ricas en energías y en ideal» como Luxemburg. José Quijano, representante del Grupo de Estudiantes Socialistas, se centró en alabar la revolución rusa que era lo que Liebknecht y Luxemburg querían hacer en Alemania. Álvarez del Vayo recordó la división entre socialistas mayoritarios y minoritarios y criticó a los primeros como responsables del crimen. Al mismo tiempo alabó a Luxemburg y Liebknecht quienes mantuvieron la integridad de la doctrina hasta en los días más difíciles. Recordó su encuentro en el Congreso de Jena y cómo Luxemburg trabajó por salir-

118. "Velada en honor de Rosa Luxemburgo y Liebknecht", El Pais, 24-01-1919, p. 3; "En la Escuela Nueva”, La Acción, 20-01-1919, p. 4; "Reuniones y sociedades", El Imparcial, 2101-1919, p. 5; "En honor de Liebknecht y Rosa Luxemburgo", El Socialista, 20-01-1919, p. 2; "Velada en honor de Rosa Luxemburgo y Liebknecht”, El Socialista, 22-01-1919, p. 2.

119. "Velada en honor de Rosa Luxemburgo y Liebknecht", Heraldo de Madrid, 21-01-1919, p. 5; "Gran velada en honor de Rosa Luxemburgo y Liebknecht”, El Socialista, 24-01-1919, p. 1. se de la excesiva teorización y aplicar el sentido práctico. Manuel Pedroso recalcó que Luxemburg y Liebknecht, a quienes había conocido personalmente, habían muerto «víctimas de un ideal» como mártires añadiendo que: «frente a la actitud de los mayoritarios - una especie de kaiserismo sin el Káiser-, dedicada a hacer una revolución con el fin único de hacer la paz, estaba la de esos dos jefes, que se disponían a hacer una revolución profunda y universal, que es la única qua podía interesarnos como españoles». Andrés Ovejero recalcó que la obra de Luxemburg y Liebknecht sobreviviría a su muerte. Por último intervino Daniel Anguiano, en representación del Comité Nacional del Partido, para el cual la mejor forma de rendirles homenaje era convirtiendo en realidad su programa. ${ }^{120}$ Fue, en definitiva y para El País, una «magnífica» velada «digna de la memoria de los mártires del socialismo». ${ }^{121}$

\section{Cuarta etapa, en recuerdo de Luxemburg}

En la última etapa las informaciones en las que apareció Luxemburg se dispersan. Apareció nombrada en relación a diferentes temas como la muerte de otros alemanes (como Kurt Eisner), la influencia del bolcheviquismo, al ser recordada en mítines de socialistas españoles, al dár-

120. "Impresiones de un acto espartaquista", $L a$ Acción, 25-01-1919, p. 5; "En la casa del pueblo. Velada en memoria de Rosa Luxemburgo y Carlos Liebknecht”, El Sol, 25-01-1919, p. 6; “A la memoria de los buenos. Rosa Luxemburgo y Carlos Liebknecht. Velada en la casa del pueblo", El Socialista, 25-01-1919, p. 1.

121. "Velada en la Casa del Pueblo", El País, 2601-1919, p. 2. 
sele su nombre a una niña o al informar de las próximas elecciones a la Asamblea Nacional alemana. ${ }^{122}$ En estas informaciones solía aparecer junto a Liebknecht ya que son reacciones a los asesinatos de ambos.

Muchas de las noticias en las que apareció Luxemburg se escribieron con motivo del juicio que tuvo lugar contra sus asesinos, que fueron, según la prensa, militares (no la muchedumbre), y que acabaron huyendo o indultados.

A parte de noticias dispersas y del juicio, dos acontecimientos hicieron recordar de nuevo a Luxemburg en la prensa madrileña. Se trata de dos mítines celebrados en la Casa del Pueblo de Madrid. El primero se celebró en junio de 1919 por la Agrupación Socialista Madrileña y el Grupo Femenino Socialista. En el acto intervinieron García Cortés, Quijano, Calvo y González quienes destacaron cómo Luxemburg, de posición contraria a la guerra, fue víctima de unos socialistas traidores que, al estar en el gobierno, iban contra la causa del proletariado al convertirse en una prolongación del imperialismo. También quisieron recordar cómo Luxemburg luchó toda su vida por un ideal que no vio realizado. ${ }^{123}$

122. "Notas del extranjero", La Lectura Dominical, 25-01-1919, p. 9; "Liebknecht había firmado un pacto con Lenine", El Sol, 06-04-1919, p. 5, "ABC en Alemania. La historia de la revolución. LXVI", $A B C$, 07-05-1919, p. 5; "Otra Rosa Luxemburgo", El Fígaro, 28-08-1919, p. 9; "La Alta Silesia y los aliados", El Fígaro, 23-091919, p. 5.

123. "En memoria de Rosa Luxemburgo", La Correspondencia de España, 12-06-1919, p. 1; "El mitin de anoche", La Correspondencia de España, 13-06-1919, p. 4; "En honor de Rosa Luxemburgo", El País, 13-06-1919, p. 1; "En memoria de Rosa Luxemburgo y Liebknecht", La Correspondencia de España, 15-06-1919, p.
El segundo mitin se celebró en enero de 1920 por el Grupo Socialista de Estudiantes con motivo del primer aniversario de los asesinatos. En él intervinieron Merino García (Secretario del Comité Nacional de Juventudes Socialistas), López y López (Presidente de la Federación Nacional de Juventudes Socialistas), Torralba Beci, Daniel Anguiano (ex diputado) y Andrés Ovejero (catedrático). En el acto «los oradores ensalzaron las figuras de los dos mártires del militarismo alemán».124 Es curioso cómo El País consideró al militarismo alemán el causante de sus muertes; sin embargo, El Sol, al informar también sobre el acto habló de los mártires del partido, pero lo puso entrecomillado, como si no compartiera esa idea.

\section{Conclusiones}

Tras el análisis de las noticias cabe preguntarse qué imagen llegó de Luxemburg a la prensa madrileña o, siguiendo la teoría de la agenda-setting, cuáles fueron los calificativos que de Luxemburg llegaron a los madrileños y con los que estos construyeron su realidad. A partir de una época depende de a qué publicación se lea, pues según las publicaciones sean liberales o conservadoras 0 , durante la Guerra Mundial, aliadófilas o germanófilas, la imagen fue diferente. Aún así hay tres pilares comunes en la imagen de Luxemburg en cualquier periódico y en cualquier época: 1) su importancia dentro del

5; "En la Casa del Pueblo. Velada a la memoria de Rosa Luxemburgo", El Sol, 15-06-1919, p. 8.

124. "En honor de Rosa Luxemburgo y Liebknecht”, El País, 25-01-1920, p. 3; "Los estudiantes socialistas. Mitin en memorias de Carlos Liebknecht y Rosa Luxemburgo", El Sol, 25-01-1920, p. 3 . 
socialismo alemán; 2) la ausencia de una explicación teórica; y 3) su género.

En primer lugar, su importancia como socialista. Hayan aceptado o no sus teorías y sus métodos, el hecho de que la prensa destacara su nombre hace ver que la consideraban como alguien importante $\mathrm{o}$, en términos periodísticos, noticiable. Lo que hiciera o dijera Luxemburg era lo suficientemente meritorio como para aparecer en los impresos y no otra noticia u otra persona en su lugar. Este reconocimiento por parte de los periódicos no fue instantáneo, sino progresivo alcanzando su máximo nivel en los años de la Primera Guerra Mundial. Pero es destacable que la primera referencia de ella en los periódicos fuera en 1899, es decir, cuando tenía 28 años y cuando solamente llevaba un año en Alemania y ya entonces se la identificaba como uno de los "hombres más notables del socialismo alemán".

En segundo lugar, las informaciones de la prensa no se centraron en explicar o profundizar en sus teorías. Se dijo de ella que estaba en contra del revisionismo y de la guerra, pero no se explicó su visión del socialismo ni sus ideas económicas. Hubo excepciones, como la conferencia a la que acudió Fabra Rivas, o pinceladas en algunos artículos, pero fueron pocas. La explicación de esta falta de profundización puede estar en que la mayor parte de las informaciones sobre Luxemburg fueron en base a impresiones que otros tuvieron de ella. Es decir, conocemos a Luxemburg a través de terceros como Álvarez del Vayo o Pedroso. Esto supone que lo importante no sea lo que dijo ella, sino lo que otros quisieron destacar de lo que ella dijo o de lo que ella era. $Y$, a menudo, lo que se quiso resaltar no fueron las teorías económicas, difíciles de explicar, sino los aspectos más curiosos, como que se enfrente a su partido, tenga problemas físicos o sea de origen judío. De hecho, en un mitin tras su muerte, una oradora dijo que de ella solamente conocía un trabajo.

En tercer lugar, su género. Luxemburg fue identificada a menudo porque era una mujer. Expresiones como "si la Rosa fuera hombre", "débil por su sexo", "prestigio varonilmente ganado" o "viriles energías" hacen ver que no era considerada de forma igualitaria a los hombres. De hecho, la mayoría de sus apariciones $(94,44 \%)$ los fueron con nombre y apellido, mientras que compañeros hombres fueron identificados solo con el apellido como le pasó a Liebknecht (solo el 10,91\% de sus apariciones las hizo con nombre y apellido).

Más allá de estas similitudes, la imagen de Luxemburg fue, en un primer momento (hasta la Primera Guerra Mundial) de una luchadora perdedora. Luchadora porque se enfrentó a la mayoría de su partido con sus propuestas, pero perdedora porque no consiguió que estas salieran adelante: no logró que el partido se alejara de los partidos burgueses, ni que aceptara recurrir a la huelga general, ni que se pronunciara en contra de la guerra.

A partir de la Primera Guerra Mundial la prensa madrileña, en función de su ideología, mostró una imagen diferente de Luxemburg. La primera de estas diferencias no fue tanto lo que dijo, sino cómo lo dijo, porque en la prensa conservadora la cantidad de noticias sobre Luxemburg fue menor que en la prensa liberal. Fue en estas publicaciones donde la mayor parte de noticias tuvieron cabida para destacar su pacifismo y su posición contraria a la mayoría del partido (que había apoyado la guerra), considerados en términos positivos. Estos dos aspectos de Luxem- 
burg, su posición contraria a la guerra y formar parte de la minoría del partido, fueron los que más empleó la prensa para identificarla, lo que demuestra que en aquellos años los periódicos estaban más centrados en la contienda mundial que en lo que defendía Luxemburg, de ahí el no profundizar en sus ideas.

Fue en la prensa liberal también donde más reacciones hubo a su asesinato. En general, fueron informaciones que engrandecieron y alabaron su vida y obra y la ensalzaron como una mártir de la revolución alemana.

Esta fue la imagen de Rosa Luxemburg que apareció en la prensa madrileña contemporánea. Una imagen a tener muy en cuenta porque fue líder de un movimiento comunista que se temió llegara a España. Primero fue en Rusia con la revolución bolchevique, luego en Alemania con el movimiento espartaquista; muchos se preguntaban si podría ser la siguiente España. Si en aquella época el temor era a que las ideas comunistas fueran Ilegando a diferentes países, es conveniente conocer cómo sus ideas y sus líderes fueron descritos en esos países. La prensa fue uno de los principales medios para ello. Por eso es importante conocer la imagen que transmitieron los periódicos de Luxemburg. En general, y sobre todo gracias a la prensa liberal-socialista, esta fue positiva. Pero podríamos preguntarnos si hubiera seguido siendo así en caso de que hubiera triunfado el espartaquismo en Alemania. Posiblemente no. Para ello sería conveniente saber y comparar cómo describió la prensa a un líder comunista que sí estuviera gobernando un país, como podría ser Lenin. 